\title{
Comparison of Bacterial Cross-Contamination among Broiler Carcasses between Commercial and Non-Commercial Processed System and Its Public Health Implications
}

\author{
Prudence Mpundu1,2*, Allan Rabson Mbewe², John Bwalya Muma ${ }^{3}$, Gift Mwinga Sitali1, \\ Charles Miyanda Mubita ${ }^{3}$, Musso Munyeme ${ }^{3}$ \\ ${ }^{1}$ Ministry of Health, Levy Mwanawasa Medical University, Lusaka, Zambia \\ ${ }^{2}$ Department of Environmental Health, School of Public Health, University of Zambia, Lusaka, Zambia \\ ${ }^{3}$ Department of Disease Control, School of Veterinary Medicine, University of Zambia, Lusaka, Zambia \\ Email: *prudencezimba@gmail.com
}

How to cite this paper: Mpundu, P., Mbewe, A.R., Muma, J.B., Sitali, G.M., Mubita, C.M. and Munyeme, M. (2021) Comparison of Bacterial Cross-Contamination among Broiler Carcasses between Commercial and Non-Commercial Processed System and Its Public Health Implications. Open Journal of Veterinary Medicine, 11, 1-13. https://doi.org/10.4236/ojvm.2021.111001

Received: November 26, 2020

Accepted: January 22, 2021

Published: January 25, 2021

Copyright $\odot 2021$ by author(s) and Scientific Research Publishing Inc. This work is licensed under the Creative Commons Attribution International License (CC BY 4.0).

http://creativecommons.org/licenses/by/4.0/

\begin{abstract}
Objectives: This study aimed to conduct a comparative assessment of bacterial cross-contamination in commercial and non-commercial processing plants including associated risk factors for bacterial contamination. Study Design: This was analytic cross sectional survey on bacterial contamination of broiler carcasses between different processing systems. Introduction: Zambia, like most African and Asian Countries, still practices "live-open non-commercial broiler carcass processing systems" besides the "closed abattoir based systems". However, shelf life, spoilage and hygiene levels have been postulated to vary based on the type of processing system. Live-open non-commercial processing systems are popular among majority consumers owing to their perceived "freshness", compared to commercially dressed chickens. In between, consumers have to balance freshness and quality assurance. Ultimately, this becomes inert, remotely but an important public health issue. However, lack of empirical evidence on safety levels to guide consumer product selection leaves them to speculation. It is this need to close this gap that created an impetus for us to undertake this study. Methods: Biological samples were collected before carcass wash and after carcass wash alongside a structured questionnaire that gathered risk-associated data. Standard microbiological enumeration methods were used to isolate bacteria and enumerate contamination. Results: Broiler carcasses processed from "open" non-commercial systems were more contaminated (45.6\%) than "closed-abattoir" commer-
\end{abstract}


cially processed systems (35\%). Escherichia coli were major contaminants (71.3\%) and few Salmonella spices (typhi or para-typhi) in 1.3\%. Risk analysis indicates washing (method) of carcasses at commercial systems was significantly more risky for contamination than non-commercial ones. Major sources of contamination were "distance from water sources". Increased volume of slaughters per day ( $>15,000$ birds) for commercial systems accounted for increased cross-contamination, particularly, distance from water source was a major risk factor for contamination.

\section{Keywords}

Bacterial, Broiler Carcasses, Commercial Processing, Non-Commercial Processing

\section{Introduction}

Zambia, like most African and Asian Countries has two main types of poultry processing classified under commercial and non-commercial systems [1]. Whilst food inspection systems are in place in commercial abattoirs, non-commercial systems have little to no meat inspection services conducted. Presumptively, it is assumed that birds processed from commercial systems are likely to be hygienically dressed than those from non-commercial systems. Nevertheless, meat inspection in commercial processing systems focuses mostly on visible defects and quality of carcasses with no microbiological assessment of carcass contamination [1]. On the other hand, the problem of possible cross-contamination despite the carcass being inspected may have far-reaching consequences when it comes to shelf life and possible food spoilage [2]. The current scenario is further complicated mainly by the lack of risk-based meat inspection practices along the poultry processing abattoirs value chain in Zambia [2].

The demand for Broiler meat consumption has increased both in developing and developed nations [3]. This has been attributed due to affordability including availability of small packaging of chicken parts, the rapid rate of maturity, increased supply and existence of quick non-commercial processing systems [3]. However, unregulated production of mass broiler carcasses, especially at a small scale in "backyards" and "open-markets" in the absence of any inspection services increases public health threats [1]. The problem is not only restricted to non-commercial processing as current meat inspection methods conducted in commercial abattoirs are not able to detect possible pathogens and processing flaws that can result in cross-contamination of entire batches and lots [1] [2]. Broiler meats are widely accepted across religion, cultural and traditional diversity; it has remained the major source of protein for the greater majority of the world's population [4]. The need for improvement as well as the introduction of risk-based meat inspection cannot be overemphasized [4]. Additionally, the production of poultry inclusive of the products has more than quadrupled in the 
last decade in Zambia [4]. This has seen rapid increase and expansion of the poultry sector with an estimated 6 million broiler birds being consumed annually [4]. According to Munang'andu and coworkers, the annual production rate was estimated at 81.4 million $\mathrm{kg}$ in the year 2008 and they projected this figure to quadruple in just under a decade [5].

Despite recorded success in the exponential increase in poultry production, on the contrary, most of the poultry being produced is reared under poor and unhygienic environments [5]. Studies have indicated that both spoilage and pathogenic microorganisms tend to be disseminated and incubated mostly during the growing phase and become potential contaminants during the processing phase [6]. This observation is critical when it comes to processing and quality assurance systems put in place to ensure safe, sound and wholesome product [6]. However, some of these processing operations done in the absence of good hygienic practices are more likely to contribute to increased cross-contamination with microorganisms [7]. Similarly, hygiene and contamination levels of final products have been postulated to directly depend on the primary production level and exacerbated at the secondary production level [8]. Consumers prefer Live-open non-commercial processing systems as they are deemed to offer "fresh table birds." However, with further assumptions that dressed chickens in chain stores are believed to be sold almost at the end of their shelf lives [9]. Nevertheless, the lack of underpinning empirical evidence to guide consumer's choices with regards to production systems likely to produce chickens with acceptable safety levels has left them to depend on mere speculation [10]. In such circumstances, purchase of chickens is mainly according to accessibility and to the greater extent dependent on cost implications and rather than food safety concerns [10]. These assertions are according to earlier studies done that were able to show some degree of variations in contamination levels across abattoirs that had strict food control systems like the hazard analysis critical control points (HACCP) to those that had none [2]. However, in most developing countries, non-commercial production systems to some extent, may not have pre-requisite good manufacturing systems in place which may comprise manufacturing process [11] [12].

The major bacteria in poultry is the Salmonella species (spp.) and Escherichia coli (E. coli) which is mostly shed in the faeces and easily survives on the feathers as well as the skin [6] [13]. These are among the common bacterial microorganisms documented to reside within the gastrointestinal tracts of several domestic animals as normal flora including in chickens [11]. Salmonella typhii has become a common cause of mortality among those infected through foodborne infections [14]. A range of domestic and wild animals including poultry have been shown to carry Salmonella spp. [14]. Similarly, the majority of the types of E. coli are harmless, but few may cause clinical disease in people and resulting mostly in diarrhea [8]. Despite all efforts to prioritize food safety, poultry and poultry products still rank on top in foods associated with diseases of public 
health importance globally [13]. Therefore, statistics give impetus to investigate in a more thorough and detailed manner the environments were these chickens are processed, kept or stored after processing in relation to processing systems [6].

\section{Methods}

\subsection{Sampling and Sample Size Calculation}

A cross-sectional study was conducted in Lusaka Province which is also a capital city of Zambia in November 2016 to March 2017. The food inspection manual of the Food and Drugs Act Cap 3032009 was used to calculate the sample size for bacteriological analysis using the daily commercial processing and stand throughputs [15]. The total maximum throughput for commercial processing was 20,000 birds per day while at the non-commercial 100 birds per stand were being processed. According to the inspection manual guideline 2009 the recommended sample size using this range was 5 dressed chickens to be swabbed per batch. A batch meant quantity of chickens that had the same environmental factors such as same owner and origin. A total of 160 surface and cloaca dressed chicken swabs were collected before carcass wash and after carcass wash divided equally as 80 per site. The sites were picked based on a central location for commercial processing and for non-commercial processing it was based on the number of chicken traders. At commercial processing site circular systematic random sampling was used to pick a chicken for swabbing while at the non-commercial processing, simple random sampling was utilized to pick the stands. Furthermore, pieces of chicken/whole chicken were randomly picked from the stands through shuffling before the next pick was done. The non-commercial processing and commercial processing system comprised of the sampling frame/population target $(N)$ were the sample population $(n)$ was selected. A total of three different batches were sampled at the end of the sampling period which represented three poultry sources/origins both from the commercial processing and non-commercial processing systems.

\subsubsection{Risk Associated Information}

A total number of 261 structured questionnaires were administered to food handlers from the commercial processing system and non-commercial processing system using the estimated prevalence value of $57.8 \%$ obtained from a study of E. coli contamination of chicken carcasses in commercial processing system from a previous study [16].

This was proportionally allocated to two sub-populations as follows: 174 to the commercial processing system and 87 to the non-commercial processing system.

\subsubsection{Water Samples}

Quality control was measured by collection of water that was being used at the 
commercial processing and the non-commercial processing systems. Water samples were collected before carcass wash and immediately after the carcasses were washed. The water samples were taken to the laboratory and analyzed together with the biological samples.

\subsection{Sample Examination}

\section{1) Methods (detection and enumeration)}

\section{2) Isolation and identification of Salmonella}

Sample swabs were resuscitated by inoculating the sample swabs in $9.0 \mathrm{mls}$ of Peptone broth (HIMEDIA) and incubated at $37^{\circ} \mathrm{C}$ for 24 hours, from which one milliliter was gotten and cultured into $10 \mathrm{mls}$ of Salmonella enrichment broth (Rappaport Vassiliadis, HIMEDIA) for 48 hours at $44^{\circ} \mathrm{C}$. Thereafter, using a loopful of Salmonella enrichment broth was cultured on Xylose Lysine Deoxycholate (XLD) agar (HIMEDIA) for 24 hours at $37^{\circ} \mathrm{C}$. Only colonies with slight transparent red halo with pinkish reddish zones and black centers were subjected to biochemical tests. Biochemicals included; Triple Iron Sugar (TSI), Urea, Methyl red, Voges Proskauer, Citrate and Sulphide Indole Motility (SIM) medium as per standard test protocols earlier described [16]. Isolates that were considered positive (TSI positive, urease negative, indole negative, methyl red positive, Voges Proskauer negative, and citrate test positive respectively) were subcultured on Nutrient agar (HIMEDIA) at $37^{\circ} \mathrm{C}$ for 24 hours and isolates were stored in $10 \%$ glycerol peptone water at $-20^{\circ} \mathrm{C}$.

\section{3) Enumeration of Escherichia coli}

The pour plate method on Eosin Methylene Blue agar (EMB) was employed to enumerate $E$. coli at a correct dilution factor. One $(1 \mathrm{ml})$ of each dilution was poured on sterile molten EMB agar (HIMEDIA) and incubated at $44^{\circ} \mathrm{C}$ for 24 hours. The shiny distinct metallic colonies were counted per CFU [16].

Suspected $E$. coli colonies were positive on Triple Iron Sugar, urea, citrate and Sulphide Indole Motility (SIM) medium [16].

Water samples collected were equally investigated for Salmonella and E. coli using outlined methods above.

\subsection{Data Collection Techniques and Tools}

Bacteriological sample collection was based on bacterial contamination, structured questionnaires used to assess risk factors like hygiene practices, training in food safety, insanitary conditions including triangulation by use of a checklist.

\subsection{Statistical Analysis}

The data obtained from the study was entered in the Excel ${ }^{\circledR}$ spreadsheet and imported in Stata ${ }^{\circledast}$ software (Stata Corporation, College Station, TX, USA). The analysis was done in stata. Pearson's chi-square test was used firstly, univariate analysis by way of cross-tabulations which was followed by multiple logistic re- 
gressions.

\section{Results}

\section{1) Descriptive Analysis}

Out of 160 chicken carcasses sampled, it was found that Salmonella accounted only for $2(1.3 \%)$ whilst $E$. coli contamination accounted for 114 (71.3\%). When the source of chickens was considered, commercially processed chicken's revealed lower rate at $35.0 \%$ compared to non-commercial processing system at $45.6 \%$ contamination rate (Table 1 ).

Origin of chicken tabulated against source (Commercial/Non-commercial)

A total of 160 chickens were sampled with 53 (33.1\%) coming from the same origin/owner in-grown by the abattoirs. Further 107 (66.9\%) chickens came from various origin/owner, inclusive back yard poultry and local small farmers. When the origin of chicken was tabulated against the source, the result of the chi-square analysis for the relationship involving bacterial contamination status was statistically significant at $5 \%\left(\chi^{2}=106.7, \mathrm{p}<0.001\right)$ (Table 2$)$.

Table 3 and Table 4 indicate univariate and multivariable factors associated with bacterial contamination across the two processing systems.

2) Bacterial contamination in water samples is indicated see Table 5.

Table 1. Commercial processing and Non-commercial processing systems $(n=160)$.

\begin{tabular}{cccccc}
\hline & E. coli & Frequency & & & \\
\cline { 2 - 3 } Site & $\begin{array}{c}\text { Not contaminated } \\
(\%)\end{array}$ & $\begin{array}{c}\text { Contaminated } \\
(\%)\end{array}$ & Total (\%) & $\chi^{2}$ & P value \\
& $24(15.0)$ & $56(35.0)$ & $80(50.0)$ & & \\
\hline Commercial & $7(4.4)$ & $73(45.6)$ & $80(50.0)$ & 11.5629 & 0.001 \\
Non-commercial & $31(19.4)$ & $129(80.6)$ & $160(100.0)$ & & \\
Total & & & & & \\
\hline
\end{tabular}

Table 2. Origin of chicken tabulated against source (Commercial/Non-commercial) $(n=$ $160)$.

\begin{tabular}{cccccc}
\hline Origin of chickens & $\begin{array}{c}\text { Commercial } \\
(\%)\end{array}$ & $\begin{array}{c}\text { Non-commercial } \\
(\%)\end{array}$ & Total (\%) & $\chi^{2}$ & P value \\
\hline $\begin{array}{c}\text { In-grown by the } \\
\text { abattoirs }\end{array}$ & $53(33.1)$ & - & $53(33.1)$ & & \\
$\begin{array}{c}\text { Farmers/Backyard } \\
\text { Total }\end{array}$ & $27(16.9)$ & $80(50.0)$ & $107(66.9)$ & 106.7 & 0.001 \\
& $80(50.0)$ & $80(50.0)$ & $160(100.0)$ & & \\
\hline
\end{tabular}


Table 3. Univariate; factors identified as associated to contamination in the two processing systems $(\mathrm{n}=261)$.

a) Number of poultry dressed per day

\begin{tabular}{cccccc}
\hline \multirow{2}{*}{ Site } & \multicolumn{3}{c}{ Dressed poultry } & \multirow{2}{*}{$\chi^{2}$} & $p$-value \\
\cline { 2 - 4 } & $100-10,000(\%)$ & $>100(\%)$ & Total (\%) & & \\
\hline Commercial & $174(66.7)$ & $0(0.0)$ & $174(66.7)$ \\
Non-commercial & $0(0.0)$ & $87(33.3)$ & $87(33.3)$ & 261.0 & 0.001 \\
Total & $174(66.7)$ & $87(33.3)$ & $261(100)$ & & \\
\hline
\end{tabular}

b) Availability of hand washing facilities

\begin{tabular}{|c|c|c|c|c|c|}
\hline \multirow{2}{*}{ Site } & \multicolumn{3}{|c|}{ Soap for hand washing } & \multirow{2}{*}{$x^{2}$} & \multirow{2}{*}{$p$-value } \\
\hline & Available (\%) & Absent (\%) & Total (\%) & & \\
\hline Commercial & $87(33.3)$ & $87(33.3)$ & $174(66.7)$ & & \\
\hline Non-commercial & $36(13.8)$ & $51(19.5)$ & $87(33.3)$ & 113.4462 & 0.188 \\
\hline Total & $123(47.1)$ & $138(52.9)$ & $261(100.0)$ & & \\
\hline \multicolumn{6}{|c|}{ c) Training in food safety } \\
\hline \multirow{2}{*}{ Site } & \multicolumn{3}{|c|}{ Training } & \multirow{2}{*}{$x^{2}$} & \multirow{2}{*}{$p$-value } \\
\hline & Trained (\%) & Untrained (\%) & Total (\%) & & \\
\hline Commercial & $149(57.1)$ & $25(9.6)$ & $174(66.7)$ & & \\
\hline Non-commercial & $23(8.8)$ & $64(24.5)$ & $87(33.3)$ & 90.4412 & 0.001 \\
\hline Total & $172(65.9)$ & $89(34.1)$ & $261(100.0)$ & & \\
\hline
\end{tabular}

d) Inspection of dressed chickens

\begin{tabular}{cccccc}
\hline \multirow{2}{*}{ Site } & \multicolumn{3}{c}{ Inspection of chickens before sale } & $\chi^{2}$ & p-value \\
\cline { 2 - 4 } & Inspected (\%) & Not inspected (\%) & Total (\%) & & \\
\hline Commercial & $141(54.0)$ & $33(12.6)$ & $174(66.7)$ & & \\
Non-commercial & $21(8.0)$ & $66(25.3)$ & $87(33.3)$ & 79.7500 & 0.001 \\
Total & $162(62.1)$ & $99(37.9)$ & $261(100.0)$ & & \\
\hline
\end{tabular}

e) Refrigeration of dressed chickens

\begin{tabular}{|c|c|c|c|c|c|}
\hline \multirow[b]{2}{*}{ Site } & \multicolumn{3}{|c|}{ Refrigeration of chicken } & \multirow[b]{2}{*}{$x^{2}$} & \multirow[b]{2}{*}{$p$-value } \\
\hline & Refrigerated (\%) & $\begin{array}{c}\text { Not Refrigerated } \\
(\%)\end{array}$ & Total (\%) & & \\
\hline Commercial & $174(66.7)$ & $0(0)$ & $174(66.7)$ & & \\
\hline Non-commercial & $82(31.4)$ & $5(1.9)$ & $87(33.3)$ & 10.1953 & 0.001 \\
\hline Total & $256(98.1)$ & $5(1.9)$ & $261(100.0)$ & & \\
\hline \multicolumn{6}{|l|}{ f) Water supply } \\
\hline \multirow[b]{2}{*}{ Site } & \multicolumn{3}{|c|}{ Sources of water supply } & \multirow[b]{2}{*}{$x^{2}$} & \multirow[b]{2}{*}{$p$-value } \\
\hline & $\begin{array}{l}\text { On-site water } \\
\text { source }(\%)\end{array}$ & $\begin{array}{c}\text { Off-site water } \\
\text { source (\%) }\end{array}$ & Total (\%) & & \\
\hline Commercial & $114(43.7)$ & $60(23.0)$ & $174(66.7)$ & & \\
\hline Non-commercial & $44(16.9)$ & $43(16.5)$ & $87(33.3)$ & 5.4208 & 0.020 \\
\hline Total & $158(60.5)$ & $103(39.5)$ & $261(100.0)$ & & \\
\hline
\end{tabular}


Table 4. Risk factors associated with bacterial contamination from the two processing systems.

\begin{tabular}{ccccccc}
\hline \multirow{2}{*}{ Variables } & \multicolumn{3}{c}{ Unadjusted } & \multicolumn{3}{c}{ Adjusted ( $\mathrm{n}=130)$} \\
\cline { 2 - 7 } & OR & p-value & $95 \%$ CI & OR & p-value & $95 \%$ CI \\
\hline Number of poultry dressed per day & & & & &
\end{tabular}

\begin{tabular}{|c|c|c|c|c|c|c|}
\hline $100-10,000$ & (ref) & & & (ref) & & \\
\hline $100>$ & 1.44 & 0.160 & $0.86-2.43$ & 1.9 & 0.095 & $0.89-4.10$ \\
\hline \multicolumn{7}{|c|}{ geration of dressed chickens } \\
\hline ot refrigerated & (ref) & & & (ref) & & \\
\hline Refrigerated & 0.29 & 0.274 & $0.32-2.7$ & 0.17 & 0.119 & $0.02-1.59$ \\
\hline
\end{tabular}

a) Distance of water source

\begin{tabular}{lllllll} 
Off-site water & $(\mathrm{ref})$ & \multicolumn{5}{c}{ (ref) } \\
On-site water & 1.92 & 0.011 & $1.16-3.17$ & 1.83 & 0.025 & $1.08-3.09$
\end{tabular}

b) Trained in food safety

\begin{tabular}{ccccccc} 
Trained & $(\mathrm{ref})$ & & \multicolumn{3}{c}{ (ref) } \\
Not-trained & 1.03 & 0.912 & $0.62-1.72$ & 0.83 & 0.577 & $0.43-1.61$
\end{tabular}

c) Inspection of dressed chickens

\begin{tabular}{ccccccc} 
Inspected & (ref) & \multicolumn{5}{c}{ (ref) } \\
Not inspected & 0.93 & 0.771 & $0.56-1.53$ & 0.76 & 0.412 & $0.39-146$
\end{tabular}

*Note: (ref) means "represents the 'reference category' when interpreting the OR".

Table 5. Bacterial contamination in water samples.

\begin{tabular}{cccccc}
\hline \multirow{2}{*}{ Site } & E. coli & Frequency & & & \\
\cline { 2 - 4 } & $\begin{array}{c}\text { Not contaminated } \\
(\%)\end{array}$ & $\begin{array}{c}\text { Contaminated } \\
(\%)\end{array}$ & Total (\%) & $\chi^{2}$ & P value \\
\hline Before carcass wash & $0(0.0)$ & $31(19.4)$ & $31(19.4)$ & & \\
After carcass wash & $15(9.4)$ & $114(71.3)$ & $129(80.1)$ & 0.9775 & 0.046 \\
Total & $15(19.4)$ & $145(90.6)$ & $160(100.0)$ & & \\
\hline
\end{tabular}

\section{Discussions}

Cross-contamination was surveyed in commercial and non-commercial processing poultry plants and risk factors on processed chickens at the point of sale. The present findings show that a higher proportion of contamination was observed in non-commercial processors. The major contributor to higher levels of contamination in the non-commercial processing system can mainly be attributed to poor hygiene practices such as lack of refrigeration facilities, despite possibilities 
of cross-contamination likely being high. On the other hand, the commercial processing system showed high frequency in relation to the refrigeration of the dressed chickens. Other studies have indicated the public health importance of maintaining a cold chain in high-risk foods such as dressed chickens [17]. The other major factor that could have contributed to contamination was the lack of food safety training among the food handlers mostly from non-commercial processing system as seen from the chi-square results. Studies have indicated the correlation between food safety training and the quality of the products processed [12]. Furthermore, the performance of meat inspection was equally observed to positively contribute to the existence of bacterial contamination, other studies have demonstrated the importance of inspection in relation to product quality [2]. The other notable observation in this current study was the microbiological quality of water used during processing of dressed chickens. It was observed that the water used for carcass washing had a significant role in cross-contamination. Increased levels of bacterial contamination were recorded in processors that washed their chickens in the processing system compared to those who did not. Water has been described in public health to have a straight contact factor, especially on food surfaces and bacterium in water has been documented to adhere to the foods [18] [19]. This observation augments the need for close monitoring of water quality throughout the processing phase [20]. Moreover, public health risk can only be reduced by knowledge of the factors quantitatively [21]. Generally, both the non-commercial processing and commercial processing systems yielded considerable high levels of $E$. coli causing a health risk concern in the poultry being processed [2]. On the other hand consumption of contaminated foods like poultry has been recorded to contribute significantly to public health issues linked to foodborne illnesses [21]. Furthermore, foodborne infections like Salmonellosis may be as a result of failure to adhere to good hygiene practices (GHPs) during processing, storage and final food preparation [21].

Under this particular study, Salmonella contamination was only detected in commercial processing systems and none in non-commercial systems results that are at variance with earlier works [22], where it was isolated in non-commercial processing systems. This may partly be attributed to differences in environmental factors in relation to differences in hatcheries, brooders and rearing pens where these chickens came from [8]. The other factor could be explained by the biological nature of intermittent shedding of Salmonella as well as the repressive nature of E. coli [23]. E. coli, on the other hand, was a major contaminant in both commercial and non-commercial processing systems the results are incongruent with other similar studies [2]. More contamination was observed from non-commercial processing system (45.6\%) compared to the commercial processing system (35.0\%).

The present study added that the majority of food handlers in commercial processing systems were trained in food safety which was different from 
non-commercial processing system as seen from Table 2. The two sites showed some variances in the training of food handlers this probably can also explain the reasons for these differences in contamination levels [2]. Generally, how the slaughter procedures are carried is closely related to reduction in the overall contamination of carcasses [2]. Most importantly food handlers have been reported by other writers and in public health safety of food to be among the major contributors of contamination in food industries [24].

High $E$. coli contamination was equally isolated from dressed chickens that were bought from assorted individual farms as compared to those purchased from single farm owners. This study is in agreement with an earlier study that equally revealed that dressed chickens purchased from assorted farm owners are likely to yield high contamination levels compared to those purchased from single farm owners. This was mainly attributable to the lack of hygienic standards of these environments coupled with lack of monitoring and inspections [25].

Factors recognized to influence bacterial contamination in this current study were high dressing frequency each day, lack of food safety training, absence of refrigeration including the source of water not been within the trading area. The above factors were statistically significant $(\mathrm{p}<0.05)$. The results showed that the commercial processing systems with the highest dressing frequency each day, lack of food safety training, lack of meat inspection, lack of refrigeration and having the source of water off-site the business premises, had higher probability of yielding contaminated chickens.

Conversely, risk factors that had major significance in non-commercial processing systems were the distance from the water source in relation to the trading areas. This was significant at $\mathrm{p}<0.025$ in the adjusted model, the statistical analysis showed that as the distance from the water source increased the Likelihoods of contamination remained significant even after controlling for a number of dressed poultry per day, refrigeration, training and chicken inspection. The finding of this study can mainly be ascribed to the non-commercial processing system that mostly had a source of water that was off-site from the stands in comparison to the commercial processor system with the on-site water system. In agreement to the current results other studies equally indicated distance from the water source as being a robust independent predictor of disease [26]. Furthermore, water was commonly stored in buckets including communal utensils for cleaning the dressed chickens plus other meat products. Inadequate water was recognized to be the major driver of chicken traders to ration the commodity, later compromising hygienic practices such as lack of separation between the different types of meat products. Furthermore, this might have also facilitated cross-contamination resulting in increased bacterial load on the final product [27]. Other studies have shown that most pathogens are able to survive in contaminated water, in aerosols and on equipment's [28] [29]. Moreover, some studies have reported that portable water is an essential requirement in quality assurance in processed foods including poultry [30]. Mainly if the water 
being used is clean, the chances of having uncontaminated dressed chicken are enhanced because as earlier mentioned the quality of the processed chickens is highly dependent on the quality of water used [27].

\section{Conclusion}

In conclusion, the current study elucidated higher prevalence level of bacterial contamination in broiler carcasses processed at "open" (non-commercial) systems as compared to "closed-abattoir" (commercially processed systems). Escherichia coli were the most predominant pathogen on carcasses from both systems. Further, the rinsing of pooled chicken carcasses in processing facilities was identified as the main reservoir for the origin of poultry meat contaminants. Our results can be used by Public Health regulators in the implementation of safety management systems especially in the non-commercially processed broiler carcasses.

\section{Acknowledgements}

The authors would like to express their appreciation to the following partners: Department of Environmental Health School of Public Health, University of Zambia and Department of Disease control in the school of Veterinary Medicine, University of Zambia. Additionally, we thank the two local authorities Lusaka and Chilanga councils.

\section{Author Contributions}

PM participated in the preliminary formation of the study, wrote the manuscript, performed the cleaning of the dataset and carried out the statistical analysis. MM contributed to the thorough review of the manuscript including statistical analysis coupled with interpretation. AM played a major role in the early drafting and proofreading of the manuscript. GMS contributed to manuscript writing including data analysis. JBM contributed field intellectual skill as well as developing the manuscript. CMM participated in the proofreading and giving guidance on the identification of the microorganisms under the study. The final manuscript has been approved by all authors.

\section{Ethics}

Approval for ethics was obtained from Excellence in Research Ethics Committee with reference no. (Ref.no.2016-June-015). Permission from Lusaka and Chilanga City Councils was equally sought. Confidentiality of the information was observed throughout the study.

\section{Conflicts of Interest}

The authors declare no conflicts of interest regarding the publication of this paper. 


\section{References}

[1] Djekic, I., Smigic, N., Kalogianni, E.P., Rocha, A., Zamioudi, L. and Pacheco, R. (2014) Food Hygiene Practices in Different Food Establishments. Food Control, 39, 34-40. https://doi.org/10.1016/j.foodcont.2013.10.035

[2] Mpundu, P., Munyeme, M., Zgambo, J., Mbewe, R.A. and Muma, J. (2019) Evaluation of Bacterial Contamination in Dressed Chickens at Lusaka Abattoirs. Frontiers in Public Health, 7, 19. https://doi.org/10.3389/fpubh.2019.00019

[3] CSO (2010) Census of Population and Housing National Report Available.

[4] ZBMS (2015) Investment Opportunities in the Zambia Poultry Sector.

[5] Munang'andu, H.M., Kabilika, S.H., Chibomba, O., Munyeme, M. and Muuka, G. (2012) Bacteria Isolations from Broiler and Layer Chicks in Zambia. Journal of Pathogens, 2012, Article ID: 520564. https://doi.org/10.1155/2012/520564

[6] Allen, V., Bull, S., Corry, J., Domingue, G., Jørgensen, F., Frost, J., et al. (2007) Campylobacter spp. Contamination of Chicken Carcasses during Processing in Relation to Flock Colonisation. International Journal of Food Microbiology, 113, 54-61. https://doi.org/10.1016/j.ijfoodmicro.2006.07.011

[7] Awadallah, M.A. and Suelam, I. (2014) Characterization of Virulent Listeria monocytogenes Isolates Recovered from Ready-to-Eat Meat Products and Consumers in Cairo, Egypt. Veterinary World, 7, 788-793. https://doi.org/10.14202/vetworld.2014.788-793

[8] Sousa, C. (2006) The Versatile Strategies of Escherichia coli Pathotypes: A Mini Review. Journal of Venomous Animals and Toxins Including Tropical Diseases, 12, 363-373. https://doi.org/10.1590/S1678-91992006000300002

[9] Göransson, M., Nilsson, F. and Jevinger, Å. (2018) Temperature Performance and Food Shelf-Life Accuracy in Cold Food Supply Chains-Insights from Multiple Field Studies. Food Control, 86, 332-341.

https://doi.org/10.1016/j.foodcont.2017.10.029

[10] Meng, T., Florkowski, W.J., Sarpong, D.B., Chinnan, M.S. and Resurreccion, A. (2014) Consumer's Food Shopping Choice in Ghana: Supermarket or Traditional Outlets? International Food and Agribusiness Management Review, 17, 107-130.

[11] Buncic, S. and Sofos, J. (2012) Interventions to Control Salmonella Contamination during Poultry, Cattle and Pig Slaughter. Food Research International, 45, 641-655. https://doi.org/10.1016/j.foodres.2011.10.018

[12] Chipabika, Mbewe, R.A. and Sikateyo, B. (2015) An Assessment of Food Hygiene Practices among Food Handlers in Restaurants in Kabwe District.

[13] Mohamed-Noor, S., Shuaib, Y., Suliman, S. and Abdalla, M. (2012) Study of Microbial Contamination of Broilers in Modern Abattoirs in Khartoum State. Fascicle VI-Food Technology, 36, 74-80.

[14] Kirk, M.D., Pires, S.M., Black, R.E., Caipo, M., Crump, J.A., Devleesschauwer, B., et al. (2015) World Health Organization Estimates of the Global and Regional Disease Burden of 22 Foodborne Bacterial, Protozoal, and Viral Diseases, 2010: A Data Synthesis. PLOS Medicine, 12, e1001921.

https://doi.org/10.1371/journal.pmed.1001921

[15] GRZ (2009) Food Inspection Manual of the Food and Drugs Act 2009 of the Laws of Zambia.

[16] Ahmed, H. (2014) Bacterial Contamination of Chicken Carcasses at Abattoir in Khartoum State-Sudan. Sudan University of Science and Technology College of Graduate Studies and Scientific, Khartoum. 
[17] Liggans, G.L., Boyer, M.S., Williams, L.B., Destromp, K.W. and Hoang, S.T. (2019) Food Safety Management Systems, Certified Food Protection Managers, and Compliance with Food Safety Practices Associated with the Control of Listeria monocytogenes in Foods at Restaurants. Journal of Food Protection, 82, 1116-1123.

https://doi.org/10.4315/0362-028X.JFP-18-532

[18] FS (2016) Australia New Zealand.

[19] Zweifel, C., Althaus, D. and Stephan, R. (2015) Effects of Slaughter Operations on the Microbiological Contamination of Broiler Carcasses in Three Abattoirs. Food Control, 51, 37-42. https://doi.org/10.1016/j.foodcont.2014.11.002

[20] Kirby, R.M., Bartram, J. and Carr, R. (2003) Water in Food Production and Processing: Quantity and Quality Concerns. Food Control, 14, 283-299. https://doi.org/10.1016/S0956-7135(02)00090-7

[21] Straver, J., Janssen, A., Linnemann, A., Van Boekel, M., Beumer, R. and Zwietering, M. (2007) Number of Salmonella on Chicken Breast Filet at Retail Level and Its Implications for Public Health Risk. Journal of Food Protection, 70, 2045-2055. https://doi.org/10.4315/0362-028X-70.9.2045

[22] Kaushik, P., Kumari, S., Bharti, S.K. and Dayal, S. (2014) Isolation and Prevalence of Salmonella from Chicken Meat and Cattle Milk Collected from Local Markets of Patna, India. Veterinary World, 7, 62-65. https://doi.org/10.14202/vetworld.2014.62-65

[23] Garrity, G.M. (2012) Bergey's Manual of Systematic Bacteriology: Volume One: The Archaea and the Deeply Branching and Phototrophic Bacteria. Springer Science \& Business Media, Berlin.

[24] Akabanda, F., Hlortsi, E.H. and Owusu-Kwarteng, J. (2017) Food Safety Knowledge, Attitudes and Practices of Institutional Food-Handlers in Ghana. BMC Public Health, 17, 40. https://doi.org/10.1186/s12889-016-3986-9

[25] Giombelli, A. and Gloria, M. (2014) Prevalence of Salmonella and Campylobacter on Broiler Chickens from Farm to Slaughter and Efficiency of Methods to Remove Visible Fecal Contamination. Journal of Food Protection, 77, 1851-1859. https://doi.org/10.4315/0362-028X.JFP-14-200

[26] Shaheed, A., Orgill, J., Montgomery, M.A., Jeuland, M.A. and Brown, J. (2014) Why "Improved" Water Sources Are Not Always Safe. Bulletin of the World Health Organization, 92, 283-289. https://doi.org/10.2471/BLT.13.119594

[27] Pearce, K.L., Rosenvold, K., Andersen, H.J. and Hopkins, D. (2011) Water Distribution and Mobility in Meat during the Conversion of Muscle to Meat and Ageing and the Impacts on Fresh Meat Quality Attributes-A Review. Meat Science, 89, 111-124. https://doi.org/10.1016/j.meatsci.2011.04.007

[28] Pal, A., He, Y., Jekel, M., Reinhard, M. and Gin, K. (2014) Emerging Contaminants of Public Health Significance as Water Quality Indicator Compounds in the Urban Water Cycle. Environment International, 71, 46-62. https://doi.org/10.1016/j.envint.2014.05.025

[29] Erickson, M.C., Liao, J., Cannon, J.L. and Ortega, Y.R. (2015) Contamination of Knives and Graters by Bacterial Foodborne Pathogens during Slicing and Grating of Produce. Food Microbiology, 52, 138-145. https://doi.org/10.1016/j.fm.2015.07.008

[30] Birhanu, W., Weldegebriel, S., Bassazin, G., Mitku, F., Birku, L. and Tadesse, M. (2017) Assessment of Microbiological Quality and Meat Handling Practices in Butcher Shops and Abattoir Found in Gondar Town, Ethiopia. International Journal of Microbiological Research, 8, 59-68. 